\title{
Avaliação do crescimento e da produtividade da mamoneira BRS 149 Nordestina em dois níveis tecnológicos
}

\author{
Valdere Martins dos Santos ${ }^{1^{*}}$, Henrique Guilhon de Castro ${ }^{1}$, Dione Pereira \\ Cardoso $^{1}$, Saulo de Oliveira Lima ${ }^{1}$, Tarcísio Castro Alves de Barros Leal ${ }^{1}$ e Gil \\ Rodrigues dos Santos 1
}

${ }^{l}$ Curso de Mestrado em Produção Vegetal, Fundação Universidade Federal de Tocantins - UFT; 77.400000; Gurupi - TO - Brasil.

\begin{abstract}
This study aimed to evaluate the growth and yield of castor bean cultivar Northeastern in environments of low tech and high technological level. The design was randomized blocks in factorial scheme, with five repetitions. The treatments consisted of two levels of technology and five sampling times. In the low technological level, fertilization was not used and crop irrigation and sowing was done in pits. In the high technological level, we performed a chemical fertilization, liming the soil, plowing, disking, planting in furrows and conventional sprinkler irrigation. Characteristics were evaluated plant height, stem diameter, leaf area, fresh leaf and stem dry mass of leaf and stem, leaf area ratio, leaf area index and productivity. There were significant differences between the levels of technology in all traits. In the low technological level the absence of fertilization at planting and lack of irrigation during the period of conducting the experiment, hindered the development of plants. With respect to productivity, the high technological level showed higher productivity, $3.794 \mathrm{~kg} \mathrm{ha}^{-1}$. In the low technological level, the yield was $1.683 \mathrm{~kg} \mathrm{ha}^{-1}$.
\end{abstract}

Key words: Ricinus communis, Cultivar BRS 149 nordestina, technological level

\section{INTRODUÇÃO}

A mamoneira é uma oleaginosa de relevante importância econômica para o Brasil, sendo produzida tradicionalmente em pequenas e médias propriedades, gerando emprego e renda em razão de suas inúmeras possibilidades de aplicação na área industrial, além da perspectiva de potencial energético na produção de biodiesel, tornando-se um agronegócio bastante promissor. Pela possibilidade de uso do óleo de mamona como matériaprima para a produção de biodiesel, a cultura da mamona vem apresentando elevado crescimento nos últimos anos, com expansão de novas áreas de plantio e com a adesão de maior número de produtores e indústrias a esse agronegócio (Azevedo e Lima, 2008).

Author for correspondence: valderemartins@ hotmail.com
Atualmente, as produtividades médias obtidas em cultivos extensivos da cultura, ainda estão aquém do seu real potencial produtivo devido, provavelmente, ao baixo nível tecnológico empregado por grande parte dos agricultores, com pouco ou nenhum uso de fertilizantes (Ribeiro et al., 2009).

Os estudos com a cultura da mamona têm enfatizado a importância da interação entre a planta e o ambiente. Por isso as pesquisas devem ser regionalizadas, pois um mesmo genótipo comporta-se de forma diferente quando se muda o ambiente. A produtividade da mamona pode ser influenciada, entre outros fatores, pelos arranjos e populações de plantas, sendo que essa interação também e influenciada por características do ambiente e do genótipo (Beltrão et al., 2001).

Torna-se de suma importância estudar o desempenho vegetativo e produtivo das 
cultivares quando submetidas a diferentes condições de cultivo, umas das alternativas seria a realização de diversos estudos ecofisiológicos, que fornecem dados de crescimento e permitem estimar de forma precisa às causas de variação entre plantas diferentes ou geneticamente iguais crescendo em ambientes diferentes de forma que se possam obter informações mais detalhadas (Benincasa, 2003; Cairo et al., 2008; Floss, 2008).

A análise de crescimento se baseia fundamentalmente no fato de que cerca de $90 \%$, em média, da fitomassa seca acumulada pelas plantas, ao longo do seu crescimento resulta da atividade fotossintética. Essa análise expressa às condições morfofisiológicas da planta e avalia sua produção líquida, derivada do processo fotossintético, resultado do desempenho do sistema assimilatório durante certo período de tempo (Ludwig et al., 2010).

Este trabalho teve como objetivo avaliar o crescimento e a produtividade da cultivar Nordestina da mamoneira em ambientes de baixo nível tecnológico e de alto nível tecnológico no sul do Estado do Tocantins.

\section{MATERIAL E MÉTODOS}

O experimento foi conduzido, no período de 14 de dezembro de 2009 a 5 de agosto de
2010, na estação experimental da Fundação Universidade Federal do Tocantins campus de Gurupi, localizado a $11^{\circ} 43^{\prime} 45^{\prime}$ 'S e $49^{\circ} 04^{\prime} 07^{\prime}$ ' $\mathrm{W}$, com altitude média de 287 metros. Na Figura 1, são apresentados os valores de precipitações obtidos no Laboratório de Irrigação e Drenagem, da Fundação Universidade Federal do Tocantins. A análise química da camada superficial $(0-20 \mathrm{~cm})$ foi realizada no Laboratório de Solos, Campus de Gurupi (Tabela 1).

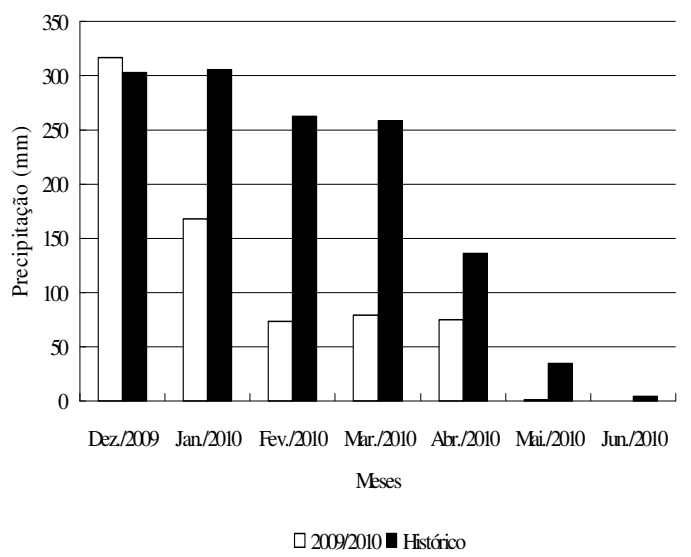

Figura 1- Valores de precipitação referentes à média histórica e ao período de condução do experimento (dezembro de 2009 a junho de 2010), obtidas no Laboratório de Irrigação e Drenagem, do Campus de Gurupi-TO.

Tabela 1. Análise química do solo. Gurupi, TO.

\begin{tabular}{|c|c|c|c|c|c|c|c|c|c|c|c|}
\hline Prof & pH & $\mathbf{P}$ & K & $\mathbf{A l}^{3+}$ & $\mathrm{H}+\mathrm{Al}$ & $\mathrm{Ca}^{2+}$ & $\mathrm{Mg}^{2+}$ & SB & $\mathbf{T}$ & $\mathbf{V}$ & MO \\
\hline cm & $\mathrm{H}_{2} \mathrm{O}$ & $\overline{\mathrm{mg} \mathrm{d}}$ & & $-\cdots$ & 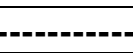 & $\mathrm{mol}_{\mathrm{c}}$ & $\mathrm{m}^{-3}$ & - & --- & $\%$ & g kg \\
\hline $0-20$ & 5,5 & 0,9 & 0,04 & 0,3 & 4,0 & 0,6 & 0,1 & 0,74 & 4,74 & 16,4 & 15 \\
\hline
\end{tabular}

Atributos químicos da profundidade de 0-20 cm; $\mathrm{pH}$ em água - Relação 1:2,5; P e K - extrator Mehich 1; $\mathrm{Al}^{3+}, \mathrm{Ca}^{2+} \mathrm{e} \mathrm{Mg}^{2+}-$ Extrator $\mathrm{KCl}\left(1 \mathrm{~mol} \mathrm{~L}^{-1}\right) ; \mathrm{H}+\mathrm{Al}$ - Extrator SMP; SB = Soma de Bases Trocáveis; $(\mathrm{T})$ = Capacidade de Troca Catiônica a pH 7,0; V - Índice de Saturação de Bases; e MO = matéria orgânica (oxidação: $\mathrm{Na} 2 \mathrm{Cr} 2 \mathrm{O} 74 \mathrm{~N}+\mathrm{H} 2 \mathrm{SO} 4$ 10N.

O delineamento experimental utilizado foi o de blocos casualizados em esquema fatorial, com cinco repetições. Cada parcela constou de três linhas espaçadas entre si de $2 \mathrm{~m}$ e 1 $\mathrm{m}$ entre plantas, totalizando $42 \mathrm{~m}^{2}$ de área total e $16 \mathrm{~m}^{2}$ de área útil. Foi considerada útil a linha central, constituída por 8 plantas da cultivar BRS 149 Nordestina. Os tratamentos foram constituídos por dois ambientes (baixo nível tecnológico e alto nível tecnológico) e cinco épocas de avaliação $(74,102,130,158$ e 186 dias após o plantio).
No baixo nível tecnológico, não foram realizadas irrigação e adubação, a semeadura foi feita em covas, utilizando três sementes por cova. Enquanto, no alto nível tecnológico realizou a correção, adubação e preparo do solo, além da irrigação por aspersão convencional. Para a correção do solo aplicou-se o calcário dolomítico (PRNT 98\%) e na adubação de plantio aplicou-se $25 \mathrm{~kg} \mathrm{ha}^{-1}$ de N, $125 \mathrm{~kg}$ ha $^{-1}$ de $\mathrm{P}_{2} \mathrm{O}_{5}$ e $75 \mathrm{~kg} \mathrm{ha}^{-1}$ de $\mathrm{K}_{2} \mathrm{O}$. Já no preparo do solo utilizou uma aração e duas gradagens, com semeadura feita 
diretamente em sulcos, com três sementes por unidade de espaçamento. Em todos os níveis tecnológicos foi realizado um desbaste aos 20 dias após a germinação, deixando uma plântula por cova. Nos dois níveis tecnológicos, o plantio foi realizado no dia 14 de dezembro de 2010.

As características avaliadas foram altura de planta, diâmetro do caule, área foliar, massa fresca da folha, massa fresca do caule, massa seca da folha, massa seca do caule, razão de área foliar, índice de área foliar e produtividade. Para avaliar a produtividade foram realizadas três colheitas. $\mathrm{Na}$ avaliação da área foliar utilizou-se a seguinte fórmula: $\mathrm{S}=0,2439 \times(\mathrm{P}+\mathrm{T})^{2,0898}$, em que: $\mathrm{S}=$ área foliar; $\mathrm{P}=$ comprimento da nervura principal; e $\mathrm{T}=$ média do comprimento das nervuras laterais (Severino et al., 2005). Para determinação da massa seca, uma amostra da massa fresca da folha e do caule, foi colocada separadamente em estufa de circulação forçada a $70^{\circ} \mathrm{C}$, até massa constante.

Os dados foram interpretados por meio de análise de variância e de regressão. Nos fatores qualitativos, as médias foram comparadas utilizando-se o teste de Tukey a $5 \%$ de probabilidade. Os modelos foram escolhidos com base na significância dos coeficientes de regressão, utilizando o teste $\mathrm{t}$ a $5 \%$ de probabilidade, e no coeficiente de determinação. A análise estatística foi feita com o auxílio do sistema computacional SAEG (Ribeiro Júnior e Melo, 2009).

\section{RESULTADOS E DISCUSSÃO}

Foi observada diferença significativa entre os dois níveis tecnológicos, para todas as variáveis avaliadas (altura de planta, diâmetro do caule, área foliar, massa fresca da folha, massa fresca do caule e massa seca da folha, massa seca do caule, razão de área foliar e índice de área foliar). $\mathrm{O}$ alto nível tecnológico proporcionou um melhor crescimento e desenvolvimento das plantas, o que pode ser explicado pelas melhores condições de cultivo proporcionadas às plantas (Tabela 2).

Na Tabela 3 são apresentadas as equações de regressão ajustadas nas variáveis nos dois níveis tecnológicos em função de cinco épocas de amostragem. Nestas variáveis foram ajustados modelos lineares nos dois níveis tecnológicos, com aumentos crescentes em função do tempo em todas as variáveis avaliadas.

$\mathrm{Na}$ variável altura houve diferença significativa entre os níveis tecnológicos em todas as épocas de avaliação (Tabela 2). Nos dois ambientes estudados foi observado que a altura aumentou linearmente em função do tempo. $\mathrm{O}$ alto nível tecnológico apresentou a maior taxa de crescimento em altura, 2,6905 cm dia ${ }^{-1}$, passando de 85,49 cm/planta, aos 74 dias após o plantio, para $386,83 \mathrm{~cm} /$ planta na última época de colheita (Tabela 3). Por outro lado a menor inclinação de reta no baixo nível tecnológico significou aumentos menores da altura em função do tempo. No baixo nível tecnológico foi verificada uma taxa de crescimento em altura de $1,766 \mathrm{~cm} \mathrm{dia}^{-1}$, passando de 38,87 $\mathrm{cm}$, aos 74 dias após o plantio, para 236,66 cm, aos 186 dias após o plantio (Tabela 3).

Segundo Ribeiro et al. (2009), avaliando a resposta da mamoneira cultivar BRS-188 Paraguaçu à aplicação de nitrogênio, fósforo e potássio encontraram alturas de planta variando de $71,37 \mathrm{~cm}$ a $82,07 \mathrm{~cm}$, aos 140 dias após plantio. Segundo os mesmos autores, a falta de uma adubação balanceada proporcionou as menores alturas.

A cultivar Nordestina é uma planta que tem tendência a excessivo crescimento vegetativo quando há disponibilidade de nutrientes e umidade no solo. No alto nível tecnológico, na ultima avaliação, aos 186 dias após o plantio, as plantas atingiram uma altura de 384,26 cm (Tabela 2), o que dificultou a colheita da cultura, diminuindo a produtividade, pois o gasto de energia para formação de folhas e caules compete com a produção das sementes. Esse fato deve ser observado na condução de plantios irrigados, onde se deve evitar o fornecimento de água em abundância e fertilizantes de forma desequilibrada, sob risco de causar crescimento excessivo em altura e diminuição na produtividade (Severino et al., 2006). 
Tabela 2. Valores médios de altura da planta (ALT), diâmetro do caule (DC), área foliar (AF), massa fresca da folha (MFF), massa fresca do caule (MFC), massa seca da folha (MSF), massa seca do caule (MSC), razão de área foliar (RAF) e índice de área foliar (IAF) da cultivar Nordestina da mamoneira, em dois níveis tecnológicos (NT) (baixo nível tecnológico e alto nível tecnológico) e cinco épocas de amostragem. Gurupi, TO.

\begin{tabular}{ccccccc}
\hline NT & Variáveis & \multicolumn{5}{c}{ Épocas de amostragem } \\
\hline & & $\mathbf{7 4}$ & $\mathbf{1 0 2}$ & $\mathbf{1 3 0}$ & $\mathbf{1 5 8}$ & $\mathbf{1 8 6}$ \\
\hline Baixo & ALT $(\mathrm{cm})$ & $46,40 \mathrm{~b}$ & $82,26 \mathrm{~b}$ & $130,26 \mathrm{~b}$ & $191,26 \mathrm{~b}$ & $239,26 \mathrm{~b}$ \\
Alto & ALT $(\mathrm{cm})$ & $86,40 \mathrm{a}$ & $151,53 \mathrm{a}$ & $249,26 \mathrm{a}$ & $309,26 \mathrm{a}$ & $384,26 \mathrm{a}$ \\
\hline Baixo & DC $(\mathrm{cm})$ & $1,58 \mathrm{~b}$ & $2,34 \mathrm{~b}$ & $2,90 \mathrm{~b}$ & $3,69 \mathrm{~b}$ & $4,20 \mathrm{~b}$ \\
Alto & DC $(\mathrm{cm})$ & $2,56 \mathrm{a}$ & $3,62 \mathrm{a}$ & $4,52 \mathrm{a}$ & $5,22 \mathrm{a}$ & $5,82 \mathrm{a}$ \\
\hline Baixo & $\mathrm{AF}\left(\mathrm{cm}^{2}\right)$ & $5174,47 \mathrm{~b}$ & $9384,82 \mathrm{~b}$ & $14966,55 \mathrm{~b}$ & $19296,55 \mathrm{~b}$ & $22296,53 \mathrm{~b}$ \\
Alto & $\mathrm{AF}\left(\mathrm{cm}^{2}\right)$ & $16471,1 \mathrm{a}$ & $33208,68 \mathrm{a}$ & $41402,58 \mathrm{a}$ & $53402,59 \mathrm{a}$ & $63402,52 \mathrm{a}$ \\
\hline Baixo & MFF $(\mathrm{g})$ & $119,20 \mathrm{~b}$ & $283,80 \mathrm{~b}$ & $419,00 \mathrm{~b}$ & $569,00 \mathrm{~b}$ & $669,00 \mathrm{~b}$ \\
Alto & MFF $(\mathrm{g})$ & $570,80 \mathrm{a}$ & $914,60 \mathrm{a}$ & $1545,80 \mathrm{a}$ & $2445,80 \mathrm{a}$ & $3667,80 \mathrm{a}$ \\
\hline Baixo & MFC $(\mathrm{g})$ & $72,40 \mathrm{~b}$ & $228,49 \mathrm{~b}$ & $556,80 \mathrm{~b}$ & $856,80 \mathrm{~b}$ & $919,00 \mathrm{~b}$ \\
Alto & MFC $(\mathrm{g})$ & $398,80 \mathrm{a}$ & $1134,40 \mathrm{a}$ & $2715,20 \mathrm{a}$ & $3915,80 \mathrm{a}$ & $5265,20 \mathrm{a}$ \\
\hline Baixo & MSF $(\mathrm{g})$ & $37,60 \mathrm{~b}$ & $78,44 \mathrm{~b}$ & $129,89 \mathrm{~b}$ & $176,39 \mathrm{~b}$ & $207,39 \mathrm{~b}$ \\
Alto & MSF $(\mathrm{g})$ & $127,60 \mathrm{a}$ & $201,21 \mathrm{a}$ & $340,07 \mathrm{a}$ & $538,07 \mathrm{a}$ & $806,91 \mathrm{a}$ \\
\hline Baixo & MSC $(\mathrm{g})$ & $22,00 \mathrm{a}$ & $50,16 \mathrm{a}$ & $150,33 \mathrm{~b}$ & $231,33 \mathrm{~b}$ & $248,13 \mathrm{~b}$ \\
Alto & MSC $(\mathrm{g})$ & $70,40 \mathrm{a}$ & $75,16 \mathrm{a}$ & $340,07 \mathrm{a}$ & $548,12 \mathrm{a}$ & $737,12 \mathrm{a}$ \\
\hline Baixo & RAF & $0,0089 \mathrm{a}$ & $0,0077 \mathrm{~b}$ & $0,0055 \mathrm{a}$ & $0,0047 \mathrm{a}$ & $0,0049 \mathrm{a}$ \\
Alto & RAF & $0,0096 \mathrm{a}$ & $0,0120 \mathrm{a}$ & $0,0062 \mathrm{a}$ & $0,0050 \mathrm{a}$ & $0,0041 \mathrm{a}$ \\
\hline Baixo & $\mathrm{IAF}$ & $0,0862 \mathrm{~b}$ & $0,1564 \mathrm{~b}$ & $0,2494 \mathrm{~b}$ & $0,3216 \mathrm{~b}$ & $0,3716 \mathrm{~b}$ \\
Alto & $\mathrm{IAF}$ & $0,2745 \mathrm{~b}$ & $0,5535 \mathrm{a}$ & $0,6900 \mathrm{a}$ & $0,8900 \mathrm{a}$ & $1,0567 \mathrm{a}$ \\
\hline
\end{tabular}

Médias seguidas pela mesma letra na coluna não diferem entre si pelo teste de Tukey a $5 \%$ de probabilidade.

Quanto à característica diâmetro do caule, foi observado nos dois níveis tecnológicos que o diâmetro aumentou linearmente em função do tempo. O alto nível tecnológico apresentou a maior taxa de crescimento em diâmetro, $0,029023 \mathrm{~cm} \mathrm{dia}^{-1}$, e o baixo nível tecnológico a menor taxa de crescimento de $0,023191 \mathrm{~cm} \mathrm{dia}^{-1}$. Os valores médios de diâmetro caulinar observados no alto nível tecnológico variaram de 2,73 a $5,98 \mathrm{~cm} \mathrm{e}$ no baixo nível tecnológico variaram de 1,63 a 4,22 cm (Tabela 3).

Com relação à área foliar, houve diferença significativa entre os níveis tecnológicos em todas as épocas de avaliação (Tabela 2). A área foliar manteve a mesma tendência das outras características avaliadas com um crescimento linear, em ambos os níveis tecnológicos. De acordo com as equações de regressão ajustadas, o alto nível tecnológico teve a maior taxa de crescimento de área foliar de 407,346 $\mathrm{cm}^{2}$ dia $^{-1}$, atingindo aos 186 dias após o plantio $64388,86 \mathrm{~cm}^{2}$ planta $^{-1}$ (Tabela 3).

A área foliar é um dos mais importantes índices de crescimento das plantas, pois, retrata o tamanho do seu aparelho assimilatório, o qual está diretamente relacionado com os processos fisiológicos das plantas. A medição da área foliar da mamoneira é uma ação importante para a pesquisa com essa cultura, por tratar-se da característica que melhor expressa à adequação, ou não, das condições ambientais ao desenvolvimento da planta (Ribeiro et al., 2009). 
Tabela 3. Equações de regressão estimadas em dois níveis tecnológicos (NT) (baixo nível tecnológico e alto nível tecnológico) nas características altura da planta (ALT), diâmetro do caule (DC), área foliar (AF), massa fresca da folha (MFF), massa fresca do caule (MFC), massa seca da folha (MSF), massa seca do caule (MSC), razão de área foliar (RAF) e índice de área foliar (IAF). Gurupi, TO.

\begin{tabular}{|c|c|c|}
\hline NT & Equações de Regressão & $\mathbf{r}^{2}$ \\
\hline & \multicolumn{2}{|c|}{ ALT $(\mathrm{cm})$} \\
\hline Baixo & $\hat{\mathrm{Y}}=-91,8043+1,76690 \mathrm{EP}^{* *}$ & 0,88 \\
\hline \multirow[t]{2}{*}{ Alto } & $\hat{\mathrm{Y}}=-113,602+2,69048 \mathrm{EP}^{* *}$ & 0,91 \\
\hline & \multicolumn{2}{|c|}{$\mathrm{DC}(\mathrm{cm})$} \\
\hline Baixo & $\hat{\mathrm{Y}}=-0,0894286+0,0231905 \mathrm{EP}^{* *}$ & 0,93 \\
\hline \multirow[t]{2}{*}{ Alto } & $\hat{\mathrm{Y}}=0,580238+0,0290238 \mathrm{EP}^{* *}$ & 0,87 \\
\hline & \multicolumn{2}{|c|}{$\mathrm{AF}\left(\mathrm{cm}^{2}\right)$} \\
\hline Baixo & $\hat{\mathrm{Y}}=-6277,16+157,70 \mathrm{EP}^{* *}$ & 0,74 \\
\hline \multirow[t]{2}{*}{ Alto } & $\hat{\mathrm{Y}}=-11377,50+407,346 \mathrm{EP}^{* *}$ & 0,76 \\
\hline & \multicolumn{2}{|c|}{ MFF (g) } \\
\hline Baixo & $\hat{\mathrm{Y}}=-230,943+4,94571 \mathrm{EP}^{* *}$ & 0,77 \\
\hline \multirow[t]{2}{*}{ Alto } & $\hat{\mathrm{Y}}=-1757,74+27,5900 \mathrm{EP}^{* *}$ & 0,89 \\
\hline & \multicolumn{2}{|c|}{$\mathrm{MFC}(\mathrm{g})$} \\
\hline Baixo & $\hat{\mathrm{Y}}=-551,206+8,29143 \mathrm{EP}^{* *}$ & 0,80 \\
\hline \multirow[t]{2}{*}{ Alto } & $\hat{\mathrm{Y}}=-3123,86+44,69 \mathrm{EP}^{* *}$ & 0,84 \\
\hline & \multicolumn{2}{|l|}{ MSF (g) } \\
\hline Baixo & $\hat{\mathrm{Y}}=-77,1969+1,56261 \mathrm{EP}^{* *}$ & 0,77 \\
\hline \multirow[t]{2}{*}{ Alto } & $\hat{\mathrm{Y}}=-384,419+6,05534 \mathrm{EP}^{* *}$ & 0,89 \\
\hline & \multicolumn{2}{|c|}{$\operatorname{MSC}(\mathrm{g})$} \\
\hline Baixo & $\hat{\mathrm{Y}}=-153,703+2,26227 \mathrm{EP}^{* *}$ & 0,80 \\
\hline \multirow[t]{2}{*}{ Alto } & $\hat{\mathrm{Y}}=-484,112+6,44933 \mathrm{EP}^{* *}$ & 0,84 \\
\hline & RAF & \\
\hline Baixo & $\hat{\mathrm{Y}}=0,0114313-0,0000391697 \mathrm{EP}^{* *}$ & 0,46 \\
\hline \multirow[t]{2}{*}{ Alto } & $\hat{\mathrm{Y}}=0,0157580-0,0000643507 \mathrm{EP}^{* *}$ & 0,57 \\
\hline & IAF & \\
\hline Baixo & $\hat{\mathrm{Y}}=-0,104617+0,00262828 \mathrm{EP}^{* *}$ & 0,74 \\
\hline Alto & $\hat{Y}=-0,189624+0,00678908 \mathrm{EP}^{* *}$ & 0,76 \\
\hline
\end{tabular}

** significativo a $1 \%$ de probabilidade, pelo teste "t".

A área foliar é um dos mais importantes índices de crescimento das plantas, pois, retrata o tamanho do seu aparelho assimilatório, o qual está diretamente relacionado com os processos fisiológicos das plantas. A medição da área foliar da mamoneira é uma ação importante para a pesquisa com essa cultura, por tratar-se da característica que melhor expressa à adequação, ou não, das condições ambientais ao desenvolvimento da planta (Ribeiro et al., 2009).

De acordo com Rodrigues et al. (2006), plantas de mamoneira bem nutridas, aos 90 dias após plantio, apresentaram área foliar em torno de $14.647,00 \mathrm{~cm}^{2}$, valor esse superior ao encontrado no baixo nível tecnológico e inferior ao alto nível tecnológico. A menor área foliar encontrada no baixo nível tecnológico está relacionada à ausência de adubação no plantio e a falta de irrigação durante o período de condução do experimento.

A mamoneira tem forte demanda por nitrogênio para seu crescimento e produção foliar, e quando cultivada sob deficiência de nitrogênio, apresenta forte redução no crescimento (Santos et al., 2004). Níveis insatisfatórios de potássio, da mesma forma que de fósforo, retardam o crescimento 
inicial da planta e provocam redução considerável na produtividade (Severino et al., 2006). A deficiência de fósforo proporciona uma redução na área foliar através da limitação do número de folhas, da ramificação da parte aérea, da redução da taxa de assimilação de carbono e da senescência prematura das folhas, limitando assim a futura produção de sementes (Marschner, 2002).

$\mathrm{Na}$ variável massa fresca da folha houve diferença significativa entre os níveis tecnológicos em todas as épocas de avaliação (Tabela 2). Nessa variável o alto nível tecnológico apresentou maiores aumentos a cada intervalo de tempo, $27,5900 \mathrm{~g} \mathrm{dia}^{-1}$, atingindo aos 186 dias após o plantio, 3374,0 $\mathrm{g} \mathrm{planta}^{-1}$. Por outro lado, no baixo nível tecnológico, a menor inclinação da reta significou aumentos menores de biomassa fresca a cada intervalo de tempo, 4,9457g dia ${ }^{-1}$ (Tabela $3)$.

Com relação à massa fresca do caule houve diferença significativa entre os níveis tecnológicos em todas as épocas de avaliação (Tabela 2). Nessa variável o alto nível tecnológico apresentou maiores aumentos a cada intervalo de tempo, 44,6900 $\mathrm{g} \mathrm{dia}^{-1}$, atingindo aos 186 dias após o plantio, 5188,48 g planta $^{-1}$ (Tabela 3). Por outro lado, no baixo nível tecnológico, a menor inclinação da reta significou aumentos menores de biomassa fresca a cada intervalo de tempo, 8,2910 g dia ${ }^{1}$.

Para a característica massa seca da folha de acordo com as equações de regressão ajustadas o alto nível tecnológico apresentou maiores aumentos a cada intervalo de tempo, 6,0553 $\mathrm{g} \mathrm{dia}{ }^{-1}$, atingindo aos 186 dias após o plantio, 714,86 g planta $^{-1}$ (Tabela 3). Por outro lado, no baixo nível tecnológico, a menor inclinação da reta significou aumentos menores de biomassa fresca a cada intervalo de tempo, $1,5626 \mathrm{~g} \mathrm{dia}^{-1}$.

Não houve na primeira e segunda época de amostragem diferenças $(P>0,05)$ entre os níveis tecnológicos quanto à variável massa seca do caule (Tabela 2). O alto nível tecnológico apresentou maiores aumentos de massa seca do caule a cada intervalo de tempo, $6,4493 \mathrm{~g} \mathrm{dia}^{-1}$, atingindo aos 186 dias após o plantio, 715,4634 $\mathrm{g} \mathrm{planta}^{-1}$ (Tabela 3). Por outro lado, no baixo nível tecnológico, a menor inclinação da reta significou aumentos menores de biomassa fresca a cada intervalo de tempo, 2,2623 g $\operatorname{dia}^{-1}$.

Para o índice de área foliar o modelo de regressão linear melhor se ajustou aos dados em ambos os ambientes (Tabela 3). Observam-se aumentos crescentes do índice foliar a partir da primeira avaliação aos 74 dias após o plantio em ambos os níveis tecnológicos estudados até a última avaliação aos 186 dias após o plantio.

$\mathrm{O}$ índice de área foliar depende do estádio da cultura; nos primeiros estádios da cultura, a área foliar é pequena, com grandes perdas de radiação que atinge diretamente o solo. Com o desenvolvimento da cultura e, por conseguinte, da área foliar, a interceptação da radiação atingira um máximo, sem haver ainda problemas de sombreamento das folhas inferiores. A partir desse ponto, quando começa ocorrer o autossombreamento, as folhas inferiores tornam-se deficitárias em termos da fotossíntese líquida, tendendo a estabilização no que diz respeito ao acréscimo de área foliar e de intensidade de acumulo de matéria seca (Heiffig, 2002).

$\mathrm{Na}$ razão de área foliar (Tabela 3), o modelo de regressão linear também melhor se ajustou aos dados em ambos os ambientes. Observou-se que há um decréscimo contínuo, ao longo do tempo se iniciando aos 74 dias após o plantio até a última avaliação, aos 186 dias após o plantio, em ambos os níveis tecnológicos. Segundo Ludwig et al. (2010) a razão de área foliar é maior no início dos períodos de avaliação, pois a planta converte maior produção fotossintética para a expansão foliar e captação de luz, declinando seus valores ao longo do ciclo (Tabela 3), devido à interferência das folhas superiores sobre as inferiores e redução da área foliar útil para a fotossíntese.

Silva et al. (2008) verificaram no estudo do crescimento na cultura de pimentão que houve diminuição da razão de área foliar ao longo do ciclo da cultura e que isso indica decréscimo na quantidade de assimilados destinados às folhas. Resultados semelhantes foram obtidos por Fontes et al. (2005) para a cultura do pimentão e Silva et al. (2009) para a cultura do girassol ornamental. 
Com relação à produtividade o alto nível tecnológico apresentou uma maior produtividade, $3.794 \mathrm{Kg} \mathrm{ha}{ }^{-1}$. No baixo nível tecnológico, a produtividade foi de $1.683 \mathrm{Kg} \mathrm{ha}^{-1}$.

A menor produtividade da mamoneira no baixo nível tecnológico está relacionada com a baixa fertilidade do solo da área experimental, característica da maioria dos Latossolos da região. Pode ser observado na Tabela 1, o baixo nível da fertilidade do solo, onde se destacaram os baixos teores de potássio, fósforo e saturação de bases.

Nas condições de Cariri do Tocantins (safra 2006/2007), Carvalho et al. (2010) obtiveram uma variação na produtividade da cultivar Nordestina de 484,05 $\mathrm{kg} \mathrm{ha}^{-1} \mathrm{a}$ 2.183,55 kg ha ${ }^{-1}$. Diniz et al. (2009) estudando o crescimento da cultivar Nordestina da mamoneira em diferentes densidades populacionais, encontraram rendimentos de grãos de $1470,99 \mathrm{~kg} \mathrm{ha}^{-1}$ no espaçamento $2,0 \mathrm{~m} \times 1,0 \mathrm{~m}$ e rendimentos de $1184,45 \mathrm{~kg} \mathrm{ha}^{-1}$ no espaçamento $2,0 \mathrm{~m} \mathrm{x}$ $2,0 \mathrm{~m}$.

Outro aspecto relacionado à baixa produtividade da cultivar Nordestina da mamoneira no baixo nível tecnológico foi à baixa precipitação observada no período de condução do experimento. Este foi fator limitante para o desenvolvimento da cultura, prejudicando o florescimento e o enchimento de grãos, resultando na redução da produtividade da mamoneira. Nos meses de março e abril, quando ocorreu o florescimento das plantas de mamoneira, a precipitação foi $38,99 \%$ inferior a média histórica da precipitação nestes meses na região sul do Estado do Tocantins.

A irrigação pode suprir as necessidades hídricas da cultura em momentos importantes de demanda de água, podendo garantir incrementos na produtividade de grãos pelo aumento na produção, número de racemos e de frutos. Desta forma, há um aumento da disponibilidade de nutrientes, aliada ao fornecimento de água em estádios importantes da cultura, com $\mathrm{O}$ favorecimento dos principais componentes da produção, proporcionando aumento na produtividade de grãos e de óleo da mamoneira (Diniz Neto et al., 2009).

O plantio tardio feito em meados de dezembro de 2009, também prejudicou a produtividade das plantas de mamona no baixo nível tecnológico devido à baixa precipitação nos meses de florescimento das plantas. Portanto, é recomendado o plantio da cultura da mamona cultivar Nordestina na região sul do Estado do Tocantins, no mês de outubro, visto que desta forma o florescimento ocorrerá nos meses de janeiro e fevereiro, onde há um histórico de maior precipitação e menor déficit hídrico.

\section{AGRADECIMENTOS}

À Coordenação de Aperfeiçoamento de Pessoal de nível Superior (CAPES) e ao Conselho Nacional de Desenvolvimento Científico e Tecnológico (CNPq), pelo apoio financeiro.

\section{RESUMO}

Este trabalho teve como objetivo avaliar o crescimento e a produtividade da cultivar Nordestina da mamoneira em ambientes de baixo nível tecnológico e de alto nível tecnológico. O delineamento foi o de blocos casualizados em esquema fatorial, com cinco repetições. Os tratamentos foram constituídos por dois níveis tecnológicos e cinco épocas de avaliação. No baixo nível tecnológico, não foi realizada adubação e irrigação da cultura e a semeadura foi feita em covas. No alto nível tecnológico, foi realizada a adubação química, calagem do solo, uma aração, duas gradagens, semeadura em sulcos e irrigação por aspersão convencional. Foram avaliadas as características altura da planta, diâmetro do caule, área foliar, massa fresca da folha e do caule, massa seca da folha e do caule, razão de área foliar, índice de área foliar e a produtividade. Houve diferença significativa entre os níveis tecnológicos em todas as características avaliadas. No baixo nível tecnológico a ausência de adubação no plantio e a falta de irrigação durante o período de condução do experimento, prejudicou o desenvolvimento das plantas. Com relação à produtividade, $\mathrm{o}$ alto nível tecnológico apresentou uma maior produtividade, $3.794 \mathrm{Kg}$ $\mathrm{ha}^{-1}$. No baixo nível tecnológico, a produtividade foi de $1.683 \mathrm{Kg} \mathrm{ha}^{-1}$.

Palavras-chave: Ricinus communis, cultivar BRS 149 nordestina, nível tecnológico

\section{REFERÊNCIAS}

Azevedo, D. M. P. e Lima, E. F. (2008), O Agronegócio da mamona no Brasil. Brasília: Embrapa Informação Tecnológica, 350p. 
Beltrao, N. E. M.; Silva, L. C.; Vasconcelos, O. L.; Azevedo, D. M. P.; Vieira, D. J. Fitologia. In: Azevedo, D. M. P.; Lima, E. F. (Ed.). (2001), O agronegócio da mamona no Brasil. Embrapa Algodão: Campina Grande; Brasilia: Embrapa Informação Tecnológica, p.37-61.

Benincasa, M. M. P. (2003), Análise de crescimento de plantas: noções básicas. 2 . Ed. Jaboticabal: FUNEP, 41p.

Cairo, P. A. R.; Oliveira, L. E. M.; Mesquita, A. C. (2008), Análise de Crescimento de Plantas. Vitória da Conquista: Edições Uesb, 72p.

Carvalho, E. V.; Sá, C. H. A. C.; Costa, J. L.; Afférri, F. S.; Siebeneichler, S. C. (2010), Densidade de plantio em duas cultivares de mamona no Sul do Tocantins. Revista Ciência Agronômica, 41, 387-392.

Diniz Neto, M. A.; Távora, F. J. A. F.; Crisóstomo, L. A.; Diniz, B. L. M. T. (2009), Adubação NPK e épocas de plantio para mamoneira. I - Componentes da produção e produtividade. Revista Ciência Agronômica, 40, 578-587.

Diniz, B. L. T., Távora, F. J. A. F., Neto, M. A. (2009), Manipulação do crescimento da mamoneira através da poda em diferentes densidades populacionais. Revista Ciência. Agronômica, 40, 570-577.

Floss, E. L. (2008), Fisiologia das plantas cultivadas: $O$ estudo que está por trás do que se vê. 4. Ed. 733p.

Fontes, P. C. R.; Dias En; Silva, D. J. H. (2005), Dinâmica do crescimento, distribuição de matéria seca na planta e produção de pimentão em ambiente protegido. Horticultura Brasileira, 23, 9499.

Heiffig, L. S. Plasticidade da cultura da soja (Glycine max (L) Merril) em diferentes arranjos espaciais. São Paulo. Dissertação (Mestrado em Fitotecnia) - Universidade de São Paulo, Piracicaba, 2002.
Ludwig, F.; Guerrero, A. C.; Fernandes, D. M.; Boas, R. L. V. (2010), Análise de crescimento de gérbera de vaso conduzida em diferentes substratos. Horticultura Brasileira, 28, 70-74.

Marschner, H. (2002), Mineral nutrition of higher plants. San Diego: Academic Press, 889p.

Ribeiro Júnior, J. I. e Melo, A. L. P. (2009), Guia prático para utilização do SAEG. Viçosa: Editora UFV, 287p.

Ribeiro, S; Chaves, L. H. G.; Guerra, H. O. C.; Gheyi, H. R.; Lacerda, R. D. (2009), Resposta da mamoneira cultivar BRS-188 Paraguaçu à aplicação de nitrogênio, fósforo e potássio. Revista Ciência Agronômica, 40, 465-473.

Rodrigues, L. N.; Nery, A. R.; Carvalho, A. P.; Fernandes, P. D.; Beltrão, N. E. M. Crescimento foliar da mamoneira irrigada com esgoto doméstico sob diferentes níveis de reposição da evapotranspiração. In: CONGRESSO BRASILEIRO DE MAMONA, 2, 2006, Aracajú.

Santos, A. C. M.; Ferreira, G. B.; Xavier, R. M.; Ferreira, M. M. M.; Severino, L. S.; Beltrão, N. E. de M.; Dantas, J. P.; Moraes, C. R. A. Deficiência de nitrogênio na mamona (Ricinus communis): descrição do efeito sobre o crescimento e a produção da cultura. In: CONGRESSO BRASILEIRO DE MAMONA, 1., 2004, Campina Grande.

Severino, L. S.; Cardoso, G. D.; Vale, L. S. (2005) Métodos para determinação da área foliar da mamoeira. Campina Grande, PB, 20p. (Embrapa Algodão. Boletim de Pesquisa e Desenvolvimento, 55.

Severino, L. S.; Ferreira, G. B.; Moraes, C. R. A.; Gondim, T. M. S.; Freire, W. S. A.; Castro, D. A.; Cardoso, G. D.; Beltrão, N. E. M. (2006), Crescimento e produtividade da mamoneira adubada com micronutrientes e micronutrientes. Pesquisa Agropecuária Brasileira, 41, 563-568.

Silva, P. I. B.; Negreiros, M. Z.; Freitas, F. C. L.; Nunes, G. H. S.; Moura, K. K. F.; Grangeiro, L. C.; Silva, P. S. L. (2008), 
Crescimento de pimentão em função de arranjos espaciais e espaçamentos na fileira. Horticultura Brasileira, 26.

Silva, T. G. G.; Zolnier, S.; Grossi, J. A. S; Barbosa, J. G.; Moura, C. R. W.; Muniz, M.

A. (2009), Crescimento do girassol ornamental cultivado em ambiente protegido sob diferentes níveis de condutividade elétrica de fertirrigação. 